\title{
Morphometric assessment of coastal lagoons in New South Wales,
}

\section{Australia}

\author{
P.E. Haines ${ }^{(1)^{*}}$, R.B. Tomlinson ${ }^{(2)}$, B.G. Thom ${ }^{(3)}$
}

(1) WBM Oceanics Australia, 126 Belford Street, Broadmeadow, New South Wales 2292, Australia

(2) Griffith Centre for Coastal Management, Griffith University, Parklands Drive, Southport, Queensland 4215, Australia

(3) NSW Department of Infrastructure, Planning and Natural Resources, Bridge Street, Sydney New South Wales 2000, Australia

* corresponding author. email address: phaines@wbmpl.com.au

Running Head: Morphometrics of coastal lagoons

Keywords: Morphometrics, intermittently open estuaries, coastal lakes, coastal lagoons, classification system, coastal management, ICOLL, New South Wales

\begin{abstract}
This paper provides a framework for the assessment of the natural sensitivity of coastal lagoons to anthropogenic and other external inputs. The assessment framework is based on analysis and consideration of morphometric characteristics of coastal lagoons, and is demonstrated in this paper using eight example intermittently open coastal lagoons from New South Wales, Australia. The framework presented extends to a rudimentary classification of the eight example coastal lagoons, relative to the other 70 or so intermittently open coastal lagoons in NSW, which can be used to provide an indication of the relative importance of these lagoons with respect to future management, such as remediation or conservation.
\end{abstract}


Morphometrics describe the physical geographic characteristics of waterways such as coastal lagoons. Morphometric parameters are relatively easy to determine, as they essentially describe the physical and topographic features of waterways. As such, morphometrics can provide a simple means to define the natural sensitivity, or vulnerability, of individual systems to external loads and other artificial (anthropogenic) modifications.

Morphometric parameters, such as waterway area, waterway volume, waterway shape and the proportion of time that the entrance is either open or closed, have been used to define three separate factors that each measures one aspect of the natural sensitivity, or vulnerability, of a coastal lagoon to external loads and other inputs. The first factor (called the Evacuation Factor) is a measure of how efficiently a coastal lagoon can remove pollutants or other inputs through tidal flushing (i.e. the tidal flushing efficiency). The second factor (called the Dilution Factor) is a measure of the relative difference between the input loads from the catchment and the resident volume of the coastal lagoon. The third factor (called the Assimilation Factor) is a measure of the degree of the water level variability in a coastal lagoon, which can subsequently influence the extent and diversity of biological processes and their capacity to assimilate external inputs.

The morphometric-based assessment and classification framework presented in this paper could be applied to any country that contains a series of similar coastal lagoons that have intermittent connections to the ocean.

\section{Introduction}

Nearly 800 estuaries throughout Australia have been classified based on their physical and environmental characteristics (Boyd et al., 1992; Digby et al., 1999; Harris et al., 2002). Estuaries subject to these national classifications have only included the larger systems (with waterway areas greater than about one hectare). The total number of estuaries in Australia would therefore be much higher. Australian estuaries have been classified based on the relative significance of river, wave and tidal energy components (Dalrymple et al., 1992; Harris et al., 2002), and show distinct patterns of estuary-type dominance in different sections of the Australian coastline. 
Within the state of New South Wales (NSW) on the south-east coast of Australia, classifications by Harris et al. (2002) and others show that estuaries are dominated by the wave and river processes. From a geomorphological perspective, NSW estuaries contain mostly barrier estuaries and saline coastal lakes, with a limited number of drowned river valleys (Roy, 1984). Barrier estuaries and saline coastal lakes (as defined by Roy, 1984) are similar geomorphologic environments, however, the coastal lakes tend to represent a less mature evolutionary state, with less terrigenous sediment infill and a sometimes intermittent connection to the ocean (Roy, 1984).

Saline coastal lakes are better known internationally as coastal lagoons (Barnes, 1980; Kjerfve, 1994), however, most definitions for coastal lagoons are broad, encompassing a range of estuarine systems that have both permanent and intermittent connection with the ocean. Within NSW, a new term "Intermittently Closed and Open Lake or Lagoon” (ICOLL) has been adopted to differentiate the intermittently open coastal systems from those that are permanently open. ICOLLs within NSW are subject to specific management considerations due to their variable entrance conditions, and the impact of the entrance condition on a range of environmental processes, including water quality and aquatic habitat structure (Griffiths, 1999; Pollard, 1994). There are about 70 ICOLLs in NSW of size greater than one hectare (Figure 1), of which approximately $70 \%$ are closed for the majority of the time. As discussed further in Section 4.4, ICOLLs tend to be either predominantly open or closed to the ocean (although all predominantly closed ICOLLs would open periodically following significant catchment runoff, and all predominantly open ICOLLs would close from time to time, particularly during extended drought conditions). The typical (dry weather) state of the entrance is a function of the interaction between the coastal (sedimentary and wave) environment and residual effects of event-based catchment runoff.

Most Australian examples of ICOLLs are found along the south-east coastline, with other isolated occurrences on the Victorian south coast, and around south-west Western Australia. Estuaries that open intermittently to the ocean are also found in many other locations around the world, particularly in Southern Africa, Mexico, New Zealand, Brazil and Uruguay. 
Coastal lagoons (and specifically ICOLLs) are considered to be the estuary type most sensitive to human intervention (Boyd et al., 1992). Their accentuated natural sensitivity is the result of a number of factors that are explored within this paper, which relate to the intermittent nature of their ocean connection. When an ICOLL entrance is closed, the system can be considered a 'terminal lake', with all volumetric catchment (freshwater) runoff captured and stored, resulting in an increase in water level and a corresponding decrease in salinity. When closed, evapotranspiration from the water surface can sometimes exceed catchment runoff, causing water levels to decrease and in extreme circumstances, can yield hypersalinity. For this reason, the biological communities of ICOLLs are euyhaline, and typically comprise fewer species but in higher abundance (Teske and Wooldridge, 2001).

This paper focuses on ICOLLs within NSW, Australia (Figure 1), being a sub-class of the more commonly known coastal lagoon estuary type. Morphometrics have been used to examine the potential sensitivity of different ICOLL physical environments to anthropogenic and other external inputs. Eight (8) example lagoons (Figure 1) have been used to demonstrate the variance in a range of morphometric parameters, which have then been used to derive a rudimentary classification system describing their sensitivity to accommodating and assimilating external inputs. The eight example lagoons consist of Wamberal, Curl Curl, Wollumboola, Durras, Coila, Murrah, Bunga and Nelson, and are primarily located on the central and south coasts of NSW, where the majority of ICOLLs are found (Figure 1).

\subsection{Need for a classification system}

Like many coastlines around the world, there is pressure for future urban development within the coastal zone of non-metropolitan NSW. Considerate and strategic urban planning is required to ensure that future development will not degrade the natural values offered by the existing coastal zone environment. Given the attractive recreational opportunities offered by coastal lakes and lagoons (pers. comm.. Chris Irons, PhD candidate, Griffith University, 2004), future land developers are likely to specifically target areas protected surrounding coastal waterways, such as ICOLLs. 
A simple yet defensible classification of the natural sensitivity of coastal lagoons is required to help managers identify which systems are likely to be more naturally sensitive, and thus more vulnerable, to the impacts of burgeoning urban development, such as eutrophication and riparian vegetation clearing. The classification can be used to help prioritise activities, controls and the need for further site-specific investigations for those coastal lagoons considered to be most at risk. Morphometrics are considered suitable for such a classification, as the parameters can be determined without the need for exhaustive assessments of individual estuaries.

In addition to NSW, Australia, it is likely that other countries that contain coastal lagoons (particularly lagoons that intermittently open to the ocean) could also benefit from the derivation of a simple morphometric based assessment and classification system to define the natural sensitivity or vulnerability of these type of estuaries to anthropogenic and other external inputs and stressors.

\section{Methodology}

In simple terms, morphometrics describe the physical geographic characteristics of a waterway. The morphometrics of a coastal lagoon influence its hydrodynamic processes, which in turn control many of the other physical, chemical and biological processes, including water quality, sedimentation and ecological structure.

Six (6) basic morphometric parameters were considered as part of this assessment, comprising i) waterway area, ii) waterway volume, iii) waterway shape, iv) tidal prism ratio, v) catchment runoff (volume and loads), and vi) Entrance Closure Index (ECI). These morphometric parameters form the basis for three (3) fundamental measures of natural sensitivity, or vulnerability of coastal lagoons, which have been termed the 'Evacuation Factor’, the 'Dilution Factor', and the 'Assimilation Factor'.

The assessment of morphometrics presented in this paper is based on comparing a range of morphometric parameters for a series of like environments. As such, the assessment provides a relative measure of natural sensitivity against other similar lagoons only. It does not provide a deterministic measure of sensitivity for 
individual lagoons in the absence of information on other lagoon environments. Given the comparative nature of the assessment, units and dimensions of the morphometric parameters and the resulting sensitivity factors are considered inconsequential to the overall assessment, providing that they are consistent from one system to the next.

\subsection{Waterway Area}

The waterway areas of the eight example ICOLLs were taken as the physical surface areas of each estuary. A standardized methodology for determining waterway area was adopted, which involved digitization from scanned 1:25,000 topographic maps. For ICOLLs that are closed from the ocean, the waterway area is dependent on the water level. As the digitized waterway area reflects only a snap-shot in time (and at a water level that is not known), the adopted waterway area values must be used and interpreted with caution, as realistically they could be both larger and smaller than the values digitized from the maps. A variation in waterway area of up to $30 \%$ could be expected in some ICOLLs as a result of variable water levels (the waterway area variability is dependent on the geomorphology and foreshore ground profile of the estuary and the degree of water level variability, which in turn is a function of the sand barrier crest elevation at the ocean entrance).

\subsection{Waterway Volume}

The waterway volumes of the example ICOLLs were taken from existing literature, and reflect the results of detailed hydrographic surveys of the lagoons. Similar to the waterway area, the resident volume of ICOLLs is dependent on the water levels within the lagoon. Reported values for waterway volumes must therefore also be used with caution, as values could vary significantly with different water levels. It is considered that volumes of ICOLLs reported in literature could vary by up to $+/-50 \%$. Consequences of this variability / error on the overall sensitivity factors have been assessed and are reported in the discussion. 


\subsection{Waterway Shape (shape function)}

The shape of an estuary has largely been overlooked in all previous classifications and assessments of Australian estuaries (e.g., Roy et al., 2001; Digby et al., 1999). This is considered a significant shortcoming, as the waterway shape is important to a number of hydrodynamic processes, such as advection and circulation, which help to define the response of a system to external inputs.

The simplest measure of shape is a comparison between the waterway perimeter and the waterway area. Lagoons with small perimeters relative to their waterway areas tend to be more 'circular' in shape, while those with large perimeters relative to their waterway areas are more 'linear' or 'dendritic'. Waterway perimeters for the eight example ICOLLs were derived from digitization of 1:25,000 topographic maps, as per the definition of their waterway areas. Variability in waterway perimeter is also expected based on the variability of water levels within the lagoon, however, as the same methods were used for determining both waterway perimeters and waterway areas, it is considered that the relative comparison between the two (i.e. the lagoon shape value) is mostly free of error.

As the morphometric assessment considers only the relative characteristics of lagoons, the shape of individual ICOLLs has been determined relative to the 'typical' shape of other similar systems. Waterway perimeter and waterway area have been compared for some 70 ICOLLs located throughout NSW, Australia, varying in size from $0.01 \mathrm{~km}^{2}$ to almost $10 \mathrm{~km}^{2}$ (Figure 2). The 'typical' waterway shape (that is, the typical waterway perimeter for a given waterway area) was defined by the curve of best fit for this comparison.

The measure of the individual ICOLL shape relative to the 'typical' ICOLL shape, has been given the term 'shape function' $(S f)$. ICOLLs with a shape equal to the typical shape are assigned a $S f$ value of unity. ICOLLs that are more circular (i.e. have a smaller perimeter compared to the waterway area) are given $S f$ values greater than unity, while ICOLLs that are more linear (i.e. have a larger perimeter compared to the waterway area) are given $S f$ values less than unity, as defined by the following equations, which have been derived from an approximation of the curve of best fit describing 'typical' shape conditions for 70 ICOLLs in NSW using a stepped linear algorithm (Figure 3): 
- For ICOLLs with a waterway area of less than $0.15 \mathrm{~km}^{2}$, sf $=\frac{4}{0.15} *$ Area $^{*}$ Perimeter $^{-1}$

- For ICOLLs with a waterway area between 0.15 and $0.8 \mathrm{~km}^{2}$,

$$
s f=\left[4+6 * \frac{(\text { Area }-0.15)}{0.65}\right] * \text { Perimeter }^{-1}
$$

- For ICOLLs with a waterway area greater than $0.8 \mathrm{~km}^{2}$,

$$
s f=\left[10+40 * \frac{(\text { Area }-0.8)}{9.2}\right] * \text { Perimeter }^{-1}
$$

Note that these equations are applicable to NSW ICOLLs only. Assessment of coastal lagoons elsewhere would need to establish area-specific equations based on the relevant curve of best fit between waterway area and waterway perimeter (as shown in Figure 2 for the NSW ICOLLs).

\subsection{Tidal Prism Ratio}

The tidal prism ratio (TPR) is defined by Dyer (1997) as $(V+P) / P$, where $V$ is the low tide volume of the estuary and $P$ is the intertidal volume (i.e. tidal prism), which can be approximated as the product of the waterway area and the tidal range. The TPR provides a rudimentary indication of the degree of tidal mixing of an estuary, as it compares the volume of the incoming marine water (i.e. the tidal prism) with the resident volume of the waterway. Given that estuaries are not fully mixed during each tide, the TPR can significantly over-estimate the degree of tidal mixing within an estuary.

For the purposes of this morphometric assessment of selected NSW ICOLLs, an assumed tidal range of 0.3 metres was adopted for the estuaries (for periods when the entrances are open). In reality, the tidal range is variable and dependent on the condition of the entrance channel and shoals, however, the tidal range still rarely exceeds a value of about $0.5 \mathrm{~m}$ in NSW ICOLLs. A constant value of 0.3 metres was adopted for this assessment to provide consistency between the lagoons, and given it considers the relative sensitivity of the lagoons only, such an assumption is reasonable. 
Calculated values for the TPR contain approximations associated with determination of the waterway volume, as discussed in Section 2.2, and the waterway area, as discussed in Section 2.1.

\subsection{Catchment Runoff}

Catchment runoff was estimated for the eight example lagoons based on the areas of different landuse types within each ICOLL catchment, and pre-defined runoff parameters for different landuse types. Discretisation of catchments into forested, rural and urban landuses, and the associated areas of each landuse, was adopted from previous site-specific studies for each catchment. Average annual runoff volumes and runoff pollutant loads were approximated for each landuse within each lagoon catchment, based on average annual catchment rainfall. Average annual volumetric and pollutant runoff parameters (Table 1) for the different landuse types, which define the proportion of rainfall that is converted to volumetric runoff and catchment pollutants, were adapted from research carried out by the federally administered, national Co-operative Research Centre (CRC) for Catchment Hydrology (Duncan, 1999).

Two (2) catchment runoff parameters were used in the morphometric assessment, average annual volumetric runoff, and average annual pollutant load (using Total Nitrogen as an indicator of catchment pollutants).

Average annual volumetric runoff was calculated as follows:

Average annual volumetric runoff = average annual rainfall $*$ [(forested area * forested volumetric runoff coefficient $)+($ rural area * rural volumetric runoff coefficient $)+($ urban area * urban volumetric runoff coefficient) + waterway area] - average annual evaporation * waterway area

Average annual catchment load was calculated as follows:

Average annual catchment runoff load $=$ average annual rainfall * [(forested area $*$ forested volumetric runoff coefficient * forested TN concentration) + (rural area * rural volumetric runoff coefficient * forested TN concentration) + (urban area * urban volumetric runoff coefficient * urban TN concentration)] 
The level of accuracy associated with determination of these morphometric parameters is considered to be reasonable, given that the catchment area is not variable (unlike the waterway area and waterway volume). Over time, the relative proportions of different landuses within some catchments will change, as rural and urban development continues to expand. For the purposes of this assessment, however, such changes would be minor. As this morphometric analysis is a comparative assessment only, variations in the adapted landuse parameters (Table 1) would not impact significantly on the outcomes.

\subsection{Entrance Closure Index}

By definition, ICOLLs are only open intermittently, however, there is a wide range of variation in the degree of 'typical' openness of ICOLL entrances. For example, some ICOLLs in NSW have not closed in living memory (including Nelson Lake), although closure is theoretically possible. At the other end of the scale, some NSW ICOLLs are open only every few years following significant rainfall (including Wollumboola and Coila Lakes). A recent extended period of drought in south-eastern Australia has lead to significant entrance shoaling in many ICOLL entrances, with complete entrance closure of some systems that were previously considered permanently open.

The Entrance Closure Index (ECI) is a new term given to the proportion of time that the entrance of an ICOLL is closed. The ECI is calculated over a long-term period, and as such, represents typical, averaged entrance conditions. The ECI values for the eight example ICOLLs were determined using a range of techniques, including records of closure held by Councils (Wamberal, Wollumboola), analysis of long-term water level data (Curl Curl, Coila), historical aerial photography interpretation (Murrah, Nelson) and existing literature (Durras, Bunga). The accuracy of the indices relates to their method of determination, which ultimately is a function of the availability of long term information on lagoon conditions. All ECI values are considered approximate, and can potentially vary on decadal scales due to dominant meteorological conditions. Future climate change may also influence long term lagoon conditions, and thus may modify ECI values in time. 
The Evacuation Factor is a dimensionless parameter that provides a relative measure of the 'tidal flushing efficiency' of an ICOLL. The Evacuation Factor is defined as:

Evacuation Factor $=[\text { shape function * tidal prism ratio * }(1-E C I)]^{-1}$

The proportion of time that the entrance is open (i.e. 1 - ECI) is required to define the evacuation factor, as tidal flushing and evacuation of resident waters can only occur when the entrance is open and oceanic water is exchanged with the lagoon. The Evacuation Factor also incorporates the waterway shape function, as the waterway shape is important in defining how well the oceanic water is mixed and advected around the lagoon. It is considered that inclusion of the shape function helps to overcome the inaccuracies associated with using the TPR in isolation, as it accounts for a variable degree of mixing within the estuary.

\subsection{Dilution Factor}

The Dilution Factor describes the efficiency of an ICOLL to receive and accommodate inputs from the catchment without significant impact on the resident condition of the waterway. Physical dilution is the primary mechanism controlling the efficiency of the ICOLL to receive and accommodate catchment inputs. Therefore, the Dilution Factor is essentially a comparison between catchment pollutant input loads and the resident volume of the lagoon. It is assumed that when the entrance is open, much of the catchment load is advected to the ocean. As such, the Dilution Factor is adjusted to consider only the proportion of time that the entrance is closed (i.e. the ECI), and that the lagoon is the terminus for all catchment runoff. The Dilution Factor is defined as:

Dilution Factor $=$ catchment runoff pollutant load $($ av. annual $) *$ waterway volume ${ }^{-1} *$ Entrance Closure Index

The Dilution Factor has units of $\mathrm{kgML}^{-1}\left(\mathrm{or} \mathrm{mgL}^{-1}\right.$ ), and essentially represents the accumulated pollutant concentration within the lagoon that is directly attributable to the average annual catchment runoff load. The Dilution Factor value does not represent a real concentration in the lagoon, but rather, a hypothetical 
concentration assuming pollutant loads are retained and accumulated within the same fixed volume of resident water.

\subsection{Assimilation (Water Level Variance) Factor}

The Assimilation Factor is a de facto measure of the average annual water level variation of an ICOLL. The Assimilation Factor is similar to the Dilution Factor, but addresses the volumetric contribution of catchment inputs rather than pollutant loads, and compares the runoff volume to the waterway area rather than the resident volume of the lagoon.

The Assimilation Factor is defined as:

Assimilation Factor $=$ catchment runoff volume (av. annual) $*$ Waterway Area ${ }^{-1} *$ Entrance Closure Index

The Assimilation Factor has dimensions of metres, and represents the effective total average annual water level rise in the lagoon. As water levels in ICOLLs only rise when the entrance is closed to the ocean, the Assimilation Factor has been adjusted to consider only the proportion of volumetric catchment runoff that occurs when the entrance is closed (i.e. includes the ECI).

\section{Results of Morphometric Assessment}

Values for the six morphometric parameters were determined for the eight example NSW ICOLLs (Table 2). The example lagoons chosen represent a diverse range in morphometric characteristics, including waterway area $\left(0.1\right.$ to $\left.6.6 \mathrm{~km}^{2}\right)$, waterway volume (18 to $\left.13,070 \mathrm{ML}\right)$, shape function (0.70 to 1.66$)$ and Entrance Closure Index (0.02 to 0.96).

Using the methods described above, the morphometric parameters have been combined to determine values for the Evacuation Factor, the Dilution Factor and the Assimilation (water level variance) Factor. Similar to the morphometric characteristics themselves, the eight example lagoons exhibit a diverse range of sensitivity factor values (Table 2). The Evacuation Factor ranged from 3.2 (Nelson) to 120.1 (Wamberal), the Dilution 
Factor ranged from $0.19 \mathrm{mgL}^{-1}$ (Nelson) to $323 \mathrm{mgL}^{-1}$ (Curl Curl), and the Assimilation Factor ranged from $0.07 \mathrm{~m}$ (Nelson) to $22.8 \mathrm{~m}$ (Curl Curl), closely followed by $22.4 \mathrm{~m}$ (Murrah). For each factor, the minimum value was assigned to Nelson Lake. With an ECI of 0.02 , Nelson Lake is considered to represent the least sensitive (or most robust) of the eight example lagoons assessed.

\section{Discussion}

Discussion of the results for selected morphometric parameters, and associated sensitivity factors, is provided in the sections below.

\subsection{Waterway Area}

An assessment of the majority of ICOLLs in NSW, totaling approximately 70 lagoons, shows that the size of the waterway area generally corresponds to the size of the contributing catchment, although there is still significant variability in this relationship, of up to two orders of magnitude (Figure 4). The comparison between waterway area and associated catchment area provides a rudimentary indication of the geomorphological state of the ICOLL. Systems with a smaller waterway area relative to the catchment area were considered more geologically mature than systems with a larger waterway area relative to the catchment area. Based on Figure 4 and the information presented in Table 1, Curl Curl, Bunga and Murrah Lagoons are considered to be more geomorphologically mature than most other NSW ICOLLs, while Coila, Wollumboola and Durras Lagoons are more youthful. The geomorphology of Wamberal and Nelson Lagoons indicates they are approximately typical of the evolution status for most NSW ICOLLs.

\subsection{Waterway Volume}

The volume of the waterway relative to the size of the catchment can also provide a rudimentary indication of the geomorphological maturity of a lagoon environment. Lagoons with relatively small volumes compared to their catchments are likely to have been more infilled by alluvial (catchment runoff) processes and thus are considered to be more evolved, or mature. 
The ratio of waterway volume to waterway area is the average waterway depth. Average depth can be considered as another (secondary) morphometric parameter, which is important for a number of biological processes that occur in coastal lagoons (Roy et al., 2001). For example, seagrass coverage in lagoons is influenced largely by the depth of the waterway, as seagrass can only grow within the photic zone. Deeper lagoons have larger portions of their bed below the photic zone and thus would have less seagrass coverage, however, shallower lagoons are likely to experience higher turbidity from wind stirring of fine-grained bed sediments, which also inhibits light penetration and seagrass productivity. Therefore, ideal seagrass conditions are expected at intermediate depths (i.e. lagoons with typical depths of approximately 1 to 2 metres).

\subsection{Waterway Shape}

The waterway shape has a significant, but little recognised, influence on the hydrodynamics of coastal lagoons, particularly lagoons that are frequently closed and rely on wind-driven circulation to drive advection and mixing processes. Relatively linear lagoons have been assigned the new term 'displacementdominated' lagoons. This term has been assigned because catchment runoff that enters the lagoon tends to push out, or displace, the resident water in the system. Following significant catchment runoff, the water quality of a displacement-dominated lagoon, starting in the upstream extremities of the waterway, can quickly reflect the quality of the inflowing runoff rather than the antecedent conditions in the lagoon prior to the event. Relatively circular lagoons have been assigned the new term 'mixing-dominated' lagoons. Catchment runoff that enters a mixing-dominated lagoon tends to become assimilated with the resident water of the lagoon prior to discharge to the ocean (if the entrance is open).

To illustrate the significance of waterway shape, combined two-dimensional numerical hydrodynamic and advection / dispersion modeling was undertaken using two different theoretical shape conditions: a linear displacement-dominated system; and a circular mixing-dominated system. In both cases, the same waterway area was adopted $\left(0.4 \mathrm{~km}^{2}\right.$ : being the median waterway area for NSW ICOLLs). The displacement-dominated model layout had a waterway perimeter of $8.2 \mathrm{~km}$, while the mixing-dominated model layout had a perimeter 
of $2.2 \mathrm{~km}$ (giving shape functions of 0.77 and 2.87 , respectively). The same tidal range of 0.3 metres was adopted for both model scenarios. The results of the numerical modeling showed that tidal exchange was up to 10 times greater (i.e. 10 times more efficient) for the mixing-dominated shape conditions compared to displacement-dominated shape conditions (as measured by the number of tides taken to reduce conservative constituent concentrations within the extremities of the model to a pre-defined proportional level).

\subsection{Entrance Closure Index}

The Entrance Closure Index (ECI) is considered a critical morphometric parameter, which has not been included in previous estuary classifications and vulnerability assessments. The inclusion of this parameter is a defining difference between this methodology and other preceding estuarine classifications (e.g. Roy, 1984; Digby et al., 1999; Roy et al., 2001).

Entrance Closure Indices for most NSW ICOLLs have been calculated using techniques similar to that adopted for the eight example ICOLLs and discussed in Section 2.6. The results (Figure 5) indicate that approximately $70 \%$ of NSW ICOLLs are mostly closed (i.e. are closed for more than $60 \%$ of the time, or have an ECI of 0.6 or greater), while $25 \%$ are mostly open (i.e. closed for less than $20 \%$ of the time, or have an ECI of 0.2 or less). Very few ICOLLs have an approximately equal proportion of time in an open and closed state, as shown in the distribution plot in Figure 5. This bimodal behaviour of ICOLL entrances is considered to be significant, however, the reasons for this behaviour are not well understood. Entrance conditions of coastal lagoons are dependent on a number of factors relating to the dominant coastal and catchment processes, as well as topographic features of the entrance and coastline, such as headlands, offshore reefs, and the presence of shallow rock underlying the entrance.

\subsection{Evacuation Factor}

Relatively large Evacuation Factor values indicate lagoons that have a poor tidal flushing efficiency, and thus cannot physically evacuate pollutants and other inputs from the water as well as other similar lagoon 
systems. ICOLLs with larger Evacuation Factors are considered to be more sensitive, or vulnerable to external inputs.

The accuracy of the Evacuation Factor values essentially relates to the accuracy of the adopted tidal prism ratio (TPR) value. The TPR is influenced by both the waterway area and the waterway volume, which are both variable in ICOLLs (dependent on water levels at the time of determination). A sensitivity analysis was carried out for the eight example ICOLLs wherein the Evacuation Factor values were recalculated based on the potential errors in determining waterway area and waterway volume (of up to 50\%). Given that there was more than one order of magnitude difference in Evacuation Factor values across the eight example ICOLLs, the sensitivity analysis showed that the relativity between lagoons was maintained regardless of the changes made to waterway area and volume.

\subsection{Dilution Factor}

Lagoons with relatively large Dilution Factors represent systems that have smaller resident volumes and/or larger catchments, and as such, are not as able to dilute inputs as effectively as lagoons with large volumes and/or small catchments (and are defined by relatively smaller Dilution Factors). Lagoons with larger Dilution Factors are considered to be more sensitive, or vulnerable, to external inputs.

As discussed in Section 4.2, lagoons with smaller resident volumes relative to their catchments are also considered to be in a more evolved geomorphological state. Increasing geomorphological maturity of a lagoon therefore results in increasing Dilution Factor values, indicating that the overall sensitivity, or vulnerability, of a lagoon is related inter alia to its geo-evolutionary state.

For the Dilution Factor algorithm presented in Section 2.8, the accuracy of the Dilution Factor values for the eight example ICOLLs relate to the accuracy of the adopted waterway volume. As indicated in Section 2.2, the waterway volumes were taken from existing literature, and typically relate the results of bathymetric survey. Given that waterway volumes are dependent on the water levels at the time survey, an accuracy of 50\% was assigned. As for the Evacuation Factor, a sensitivity analysis was carried out for the eight example 
ICOLLs wherein the Dilution Factor values were recalculated based on the potential errors (up to 50\%) in determining waterway volume. The outcomes of the sensitivity test were similar to the analysis for the Evacuation Factor, in that despite changes in the Dilution Factor values, the relativity between the example ICOLLs was maintained, and clearly highlights those lagoons that have a high dilution potential and those that do not.

\subsection{Assimilation Factor}

Lagoons with larger Assimilation Factors have a more variable water level, which results in a less stable physical environment. Therefore, lagoons with larger Assimilation Factors are considered to be more sensitive, or vulnerable, to external inputs.

It should be noted that continuous water level rise within most NSW ICOLLs cannot exceed approximately two metres, as the entrance sand berm would become overtopped and the entrance sand plug scoured and opened to the ocean. Lagoons that have Assimilation Factors greater than a value of about 2.0 essentially represent systems that, on average, would break out naturally more than once per year. Many ICOLLs in NSW, however, are not permitted to reach their natural breakout levels, and are artificially opened at lower lagoon water levels (Pollard, 1994; Griffiths, 1999).

The Assimilation Factor has been named as such, as biological productivity within lagoons (and thus its capacity to biologically assimilate external inputs) is dependent, to a degree, on the hydraulic characteristics of the lagoon (Roy et al., 2001), including the relative physical stability of the lagoon hydraulics (i.e. water level variations). As the biological communities that occur within lagoon environments are diverse and complex, the biological assimilation capacity of a lagoon would be difficult to quantify. Therefore, water level variability has been adopted as a proxy, or indicator, of the overall biological productivity within the lagoon.

The relationship between water level variability and the biological productivity within NSW ICOLLs can be demonstrated by consideration of seagrass coverage. ICOLLs that have highly variable water levels (and thus 
high Assimilation Factors) do not generally contain seagrass beds (Figure 6). Lagoons with higher Assimilation Factors would tend to have relatively rapid water level rises and would breakout often, which in some respects is considered to 'reset' the aquatic biological environment (as pelagic organisms can be flushed from the system, while epiphytes, macrophytes and benthos can become exposed to the atmosphere). The rate of water level rise in these lagoons is likely to exceed a critical rate for the establishment of seagrass (which may be defined by an Assimilation Factor value of about 10 - see Figure 6).

As for the two previous factors, the accuracy of the Assimilation Factor values was assessed by undertaking a sensitivity analysis. The Assimilation Factor is dependent on the waterway area, which as discussed in Section 2.1, is expected to have an accuracy of $+/-30 \%$. The sensitivity analysis considered such adjustments to the waterway area and again found that the relativity between the ICOLLs was maintained despite the possible inaccuracies in defining waterway area values.

\section{Classification of Lagoon Sensitivity}

For each of the morphometric factors described above, the eight example ICOLLs were assigned a classification (A to D) to describe their relative natural sensitivity. An 'A' classification represents lagoons with a high natural sensitivity to external inputs, while a ' $D$ ' classification represents the least sensitive (or most robust) lagoons. In defining numerical values representing the different classifications, consideration has been given to the morphometric factor values of all ICOLLs in NSW.

Using the same methods shown in this paper, Evacuation Factors for all ICOLLs in NSW were found to range between 2.8 and 170, while Dilution Factors ranged between 0.002 and 32.3, and Assimilation Factors ranged between 0.01 and 48. Assignment of classifications (A to D) for each factor (Table 3) was based on an equal division of the approximate maximum numerical value for that factor measured within the NSW ICOLL dataset. This approach was adopted instead of a standard quartile division with an equal number of lagoons in each classification to emphasise the significance of the relative sensitivity between the lagoons. 
Based on the Evacuation Factor results (Table 2), Wamberal and Coila are the most sensitive of the example NSW ICOLLs, while Nelson, Murrah and Bunga are the least sensitive. Based on the Dilution Factor results

(Table 1), Curl Curl and Bunga are the most sensitive of the example ICOLLs, while Nelson, Coila and Wollumboola are the least sensitive, and based on the Assimilation Factor results (Table 2), Curl Curl and Murrah are the most sensitive of the example ICOLLs and Nelson, Coila, Durras and Wollumboola are the least sensitive. In giving consideration to the results for all morphometric factors, the highest calculated classification of the three factors was adopted as the overall classification for the example ICOLLs. From this, and as shown in Table 2, it was found that the most sensitive example ICOLLs (with an 'A' classification as the maximum for one or more morphometric factors) were Curl Curl and Wamberal. The next most sensitive example ICOLLs (with a 'B' classification as the maximum for one or more morphometric factors) were Coila, Bunga and Murrah. Wollumboola was the only example ICOLL that had a 'C' classification as the maximum for one or more morphometric factors, while the least sensitive example ICOLLs (with 'D' classifications for all morphometric factors) were Durras and Nelson.

\section{Conclusions and Future Applications}

Using a series of morphometric factors calculated from basic physical and topographic characteristics, the relative sensitivity of coastal lagoons to external inputs can be interpreted. The adopted morphometric factors provide a measure of how efficiently a lagoon can remove pollutants or other inputs from the estuary through tidal flushing (via the Evacuation Factor), a measure of the relative difference between the input loads from a catchment and the resident volume of a lagoon (via the Dilution Factor), and a measure of the degree of the water level variability in a lagoon, which can subsequently influence the natural biological processes and the associated capacity to assimilate external inputs (via the Assimilation Factor). The eight example ICOLLs described in detail in this paper display a range of sensitivities based on each of these different factors.

When the morphometric assessment presented in this paper was extended to most other ICOLLs in NSW, it was found that seven (7) ICOLLs had an 'A' classification, seven (7) ICOLLs has a 'B' classification, nine (9) ICOLLs had a 'C' classification, and 33 ICOLLs had a 'D' classification. Based on this distribution, any NSW ICOLL with a classification other the ' $\mathrm{D}$ ' would be considered as more sensitive than the typical 
(median) NSW ICOLL. It was also found that, like the example ICOLL, Nelson Lake, any ICOLL that has an ECI value of 0.2 or less had a ' $D$ ' classification, thus emphasizing the importance of long-term typical entrance conditions to the overall sensitivity, or vulnerability, of ICOLLs.

A survey of natural resource managers on the NSW coast conducted by the corresponding author of this paper revealed that the entrances of more than half of the ICOLLs in NSW are artificially opened from time to time, usually to mitigate inundation effects on fringing public and private lands. It is understood that similar intervention of coastal lagoons occur elsewhere in Australia and internationally, such as South Africa (Whitfield, 1997). Artificially opening the entrance of an ICOLL at a level lower than the natural breakout range may lead to more frequent entrance openings and possible modification to the ECI value. It is not recommended that coastal lagoon entrances be opened artificially to reduce sensitivity to external inputs without thorough environmental investigation, as changing the entrance behaviour may lead to other impacts, such as drying out and terrestrialisation of fringing wetlands, increased shoaling at the entrance, and changes to macrophyte and benthos communities.

Application of the morphometric classification presented in this paper can be used to help guide management of coastal environments in the future. The relative sensitivities between a series of coastal lagoons can be used to direct attention and future remediation or conservation works, as necessary, to those systems that are considered to be most at risk to external inputs. The classification system can also be used retrospectively to demonstrate how the natural sensitivity of a system has been altered by changes that have already occurred within the catchment. The example ICOLL, Curl Curl Lagoon, is located within the urban environment of the city of Sydney. If natural (bushland) catchment parameters were adopted in the morphometric assessment rather than the urban equivalents, then the Dilution Factor for Curl Curl would reduce from 32 to 3, and the Assimilation Factor would reduce from 23 to 9. Consequently, under natural (pre-development) conditions Curl Curl would have a ' $D$ ' classification rather than the current ' $A$ ' classification.

The morphometric assessment and classification system could also be used to predict the response of a coastal lagoon to future changes. This may involve predicting the change in natural sensitivity due to a 
change of landuse within the catchment (affecting the catchment runoff parameters) or a change in entrance management (possibly affecting the ECI value).

Finally, it is emphasized that the morphometric classification presented in this paper is suited primarily to coastal lagoons that have an intermittent connection to the ocean. As each morphometric factor incorporates the ECI value, estuaries that are permanently open to the ocean will result in null values for each factor. If an assessment of the sensitivity of permanently open estuaries is to be made, similar morphometric-based factors could be used, but excluding the ECI. Care should be taken not to compare the sensitivity results between systems that are considered to be permanently open and systems that are open and closed intermittently. The morphometric classification presented in this paper could also be extended to include much smaller intermittently open coastal environments (with waterway areas less than 1 hectare).

\section{Acknowledgements}

This paper presents findings of research being undertaken by the corresponding author as a component of a PhD project through the School of Environmental and Applied Sciences, Griffith University, Australia. The authors would like to acknowledge the assistance of Luke Kidd (WBM Oceanics Australia) for undertaking the numerical modeling presented in this paper, the assistance of Rob Fearon (Coastal CRC) and David Wainwright (WBM Oceanics Australia) for reviewing the document prior to submission, and the two anonymous reviewers who provided excellent comments and suggestions for improving this paper.

\section{References}

Barnes, R.S.K., 1980. Coastal lagoons: the natural history of a neglected habitat. Cambridge. Cambridge University Press. 106pp

Boyd, R., Dalrymple, R., Zaitlin, B. A., 1992. Classification of clastic coastal depositional environments. Sedimentary Geology 80, 139-150 
Dalrymple, R.W., Zaitlin, B.A., Boyd, R., 1992. Estuarine facies models: conceptual basis and stratigraphic implications. Journal of Sedimentary Petrology 62 (6), 1130-1146

Digby, M.J., Saenger, P., Whelan, M.B., McConchie, D., Eyre, B., Holmes, N., Bucher, D., 1999. A physical classification of Australian estuaries. National River Health Program - Project E1, LWRRDC Occasional Paper 16/99 (Urban Subprogram report No. 9), Centre for Coastal Management, Southern Cross University, Lismore, 57pp.

Duncan H.P., 1999. Urban Stormwater Quality: A Statistical Overview. Cooperative Research Centre for Catchment Hydrology, Report 99/3 February 1999, ISBN 1876006 34 5, pp 10-18

Dyer K.R., 1997. Estuaries: A physical introduction. $2^{\text {nd }}$ edition, John Wiley and Sons, Chichester, pp 165166

Fischer H., Imberger J., List E.J., Koh R., Brooks N., 1979. Mixing in Inland and Coastal Waters. Academic Press, New York, 483pp.

Griffiths, S.P., 1999. Consequences of artificially opening coastal lagoons on their fish assemblages. International Journal of Salt Lake Research 8 (4), 307-327

Harris, P.T., Heap, A.D., Bryce, S.M., Porter-Smith, R., Ryan, D.A., Heggie, D.T., 2002. Classification of Australian clastic coastal depositional environments based upon a quantitative analysis of wave, tidal and river power. Journal of Sedimentary Research 72 (6), 858-870

Kjerfve, B., 1994. Coastal lagoons. In: Kjerfve, B. (Ed.). Coastal lagoon processes. Elsevier Oceanographic Series 60. Amsterdam. pp1-8 
Pollard, D.A., 1994. A comparison of fish assemblages and fisheries in intermittently open and permanently open coastal lagoons on the south coast of New South Wales, south-eastern Australia. Estuaries 17:3, 631646

Roy, P.S., 1984. NSW Estuaries: Their Origin and Evolution. In Thom, B.G. (Ed.). Coastal Geomorphology in Australia, Academic Press, Sydney

Roy, P.S., Williams, R.J., Jones, A.R., Yassini, I., Gibbs, P.J., Coates, B., West, R.J., Scanes, P.R., Hudson, J.P., Nichol, S., 2001. Structure and function of Southeast Australian Estuaries. Estuarine, Coastal and Shelf Science 53, 351-384

Teske, P.R., Wooldridge, T., 2001. A comparison of the macrobenthic faunas of permanently open and temporarily open/closed South African estuaries. Hydrobiologia 464, 227-243

Whitfield, A.K., 1997. Fish conservation in South African estuaries. Aquatic Conservation: Marine and Freshwater Ecosystems 7(1), 1-11 
Table 1. Average Annual Volumetric and Pollutant Catchment Runoff Parameters (adapted from Duncan, 1999)

\begin{tabular}{c|cc}
\hline Landuse type & $\begin{array}{c}\text { Volume } \\
\text { (proportion of rainfall } \\
\text { that is discharged to the } \\
\text { ICOLL) }\end{array}$ & $\begin{array}{c}\text { Total Nitrogen } \\
\text { concentration } \\
\left(\mathrm{mgL}^{-1}\right)\end{array}$ \\
\hline Forested & 0.15 & 0.2 \\
Rural & 0.25 & 0.6 \\
Urban & 0.35 & 1.0 \\
\hline
\end{tabular}


Table 2. Morphometric characteristics and calculated factors for the eight example NSW ICOLLs

\begin{tabular}{|c|c|c|c|c|c|c|c|c|}
\hline & Wamberal & $\begin{array}{l}\text { Curl } \\
\text { Curl }\end{array}$ & Wollumboola & Durras & Coila & Murrah & Bunga & Nelson \\
\hline Latitude $\left({ }^{\circ} \mathrm{S}\right)$ & 33.4 & 33.8 & 35.0 & 35.6 & 36.1 & 36.5 & 36.6 & 36.6 \\
\hline Area $\left(\mathrm{km}^{2}\right)$ & 0.5 & 0.06 & 5.5 & 3.9 & 6.6 & 0.85 & 0.1 & 1.1 \\
\hline Volume (ML) & 760 & 48 & 6640 & 7490 & 13070 & 570 & 18 & 860 \\
\hline $\begin{array}{l}\text { Av. Annual } \\
\text { Rainfall (mm) }\end{array}$ & 1300 & 1250 & 1250 & 930 & 970 & 870 & 870 & 870 \\
\hline $\begin{array}{c}\text { Av. Annual } \\
\text { Evapor'n (mm) }\end{array}$ & 800 & 700 & 670 & 700 & 700 & 700 & 700 & 700 \\
\hline Shape function & 1.42 & 0.76 & 1.66 & 0.70 & 1.70 & 0.90 & 0.86 & 1.18 \\
\hline $\begin{array}{c}\text { TPR } \\
\text { (dimensionless) }\end{array}$ & 0.16 & 0.33 & 0.22 & 0.12 & 0.13 & 0.31 & 0.63 & 0.27 \\
\hline $\begin{array}{l}\text { Av. Annual } \\
\text { Volumetric } \\
\text { Catchment } \\
\text { Runoff (ML) }\end{array}$ & 2290 & 2280 & 10120 & 8960 & 9630 & 31760 & 1540 & 3850 \\
\hline $\begin{array}{l}\text { Av. Annual TN } \\
\text { Catchment } \\
\text { Load (kg) }\end{array}$ & 1500 & 1940 & 3000 & 1660 & 2690 & 12080 & 400 & 810 \\
\hline $\begin{array}{c}\text { Entrance } \\
\text { Closure Index } \\
\text { (dimensionless) }\end{array}$ & 0.96 & 0.80 & 0.96 & 0.62 & 0.95 & 0.60 & 0.84 & 0.02 \\
\hline $\begin{array}{c}\text { Evacuation } \\
\text { Factor } \\
\text { (dimensionless) }\end{array}$ & 120.1 & 19.7 & 63.9 & 30.0 & 89.3 & 8.9 & 11.4 & 3.2 \\
\hline $\begin{array}{c}\text { Evacuation } \\
\text { Factor } \\
\text { Classification } \\
\end{array}$ & A & $\mathrm{D}$ & $\mathrm{C}$ & $\mathrm{D}$ & B & $\mathrm{D}$ & $\mathrm{D}$ & $\mathrm{D}$ \\
\hline $\begin{array}{l}\text { Dilution Factor } \\
\text { (mg/L) }\end{array}$ & 1.91 & 32.3 & 0.30 & 0.14 & 0.20 & 12.7 & 18.6 & 0.02 \\
\hline $\begin{array}{c}\text { Dilution Factor } \\
\text { Classification } \\
\end{array}$ & $\mathrm{D}$ & A & $\mathrm{D}$ & $\mathrm{D}$ & $\mathrm{D}$ & $\mathrm{C}$ & B & $\mathrm{D}$ \\
\hline $\begin{array}{l}\text { Assimilation } \\
\text { Factor (m) }\end{array}$ & 4.41 & 22.8 & 1.57 & 1.55 & 1.39 & 22.4 & 12.9 & 0.07 \\
\hline $\begin{array}{l}\text { Assimilation } \\
\text { Factor } \\
\text { Classification } \\
\end{array}$ & $\mathrm{D}$ & B & $\mathrm{D}$ & $\mathrm{D}$ & $\mathrm{D}$ & B & C & $\mathrm{D}$ \\
\hline $\begin{array}{c}\text { Overall } \\
\text { Classification } \\
\text { (max. of factor } \\
\text { classifications) }\end{array}$ & A & A & C & $\mathrm{D}$ & B & B & B & $\mathrm{D}$ \\
\hline
\end{tabular}


Table 3. Definition of classifications representing different levels of lagoon sensitivity

\begin{tabular}{c|ccc}
\hline & Evacuation Factor & Dilution Factor & Assimilation Factor \\
\hline A & $120+$ & $24+$ & $30+$ \\
B & $80-120$ & $16-24$ & $20-30$ \\
C & $40-80$ & $8-16$ & $10-20$ \\
D & $0-40$ & $0-8$ & $0-10$ \\
\hline
\end{tabular}




\section{Figure Captions}

Figure 1. The NSW coastline showing the locations of example ICOLLs used in this paper

Figure 2. Relationship between waterway perimeter and waterway area for most NSW ICOLLs. The position of an ICOLL on this plot is used to measure waterway shape

Figure 3. Stepped linear approximation of the curve of best fit shown in Figure 2. The vertices represent a change in the equation defining the relationship that is used to calculate shape function (Sf)

Figure 4. Relationship between catchment size and waterway size using data from most NSW ICOLLs

Figure 5. Distribution plot of Entrance Closure Indices for most NSW ICOLLs highlighting the bimodal nature of lagoon entrance as either mostly closed (with a high ECI) or mostly open (with a low ECI)

Figure 6. Relationship between the Assimilation Factor (AF) and seagrass coverage for most NSW ICOLLs. Seagrass coverage is expressed as a percentage of the waterway area that contains seagrasses 


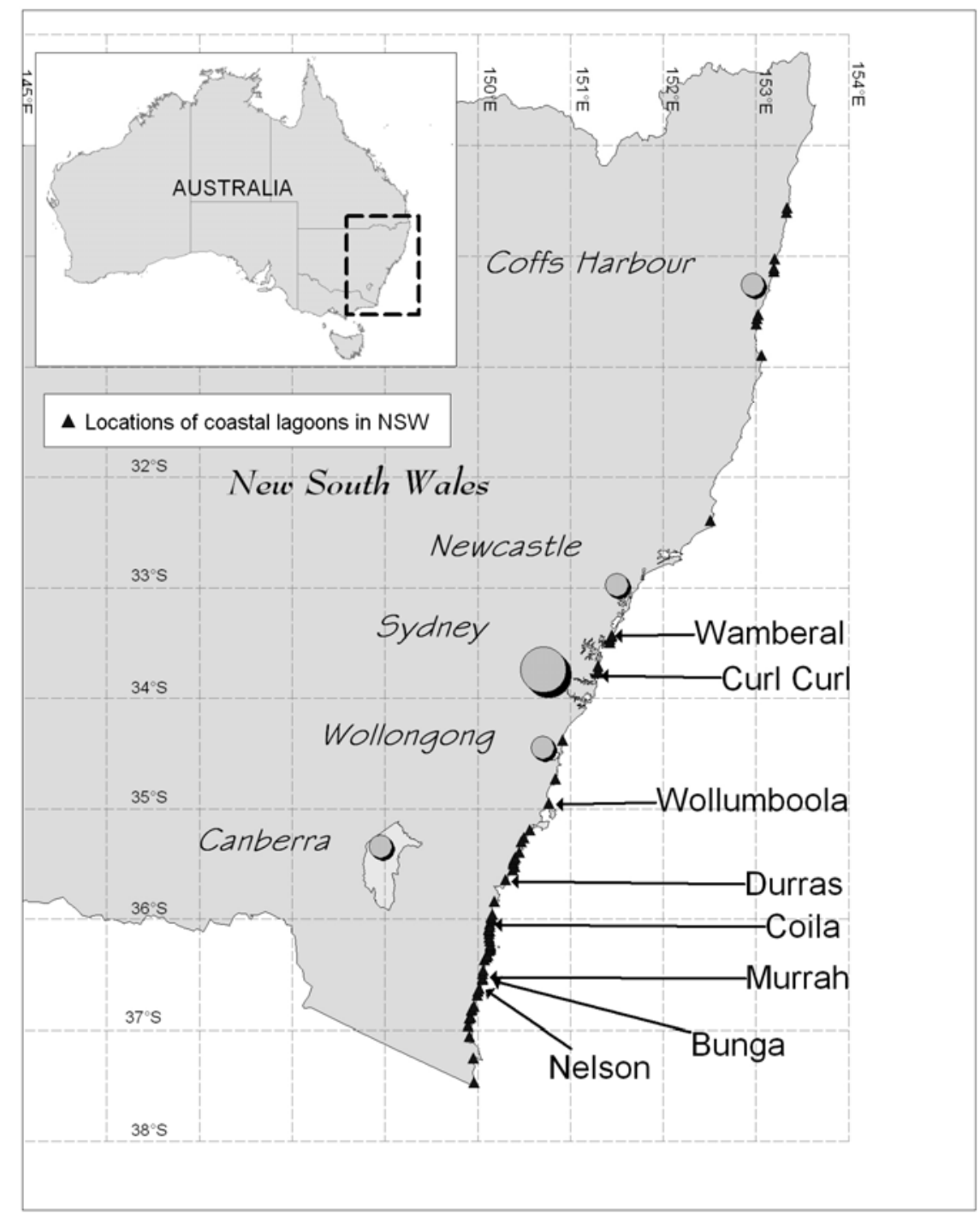

Figure 1. The NSW coastline showing the locations of example ICOLLs used in this paper 


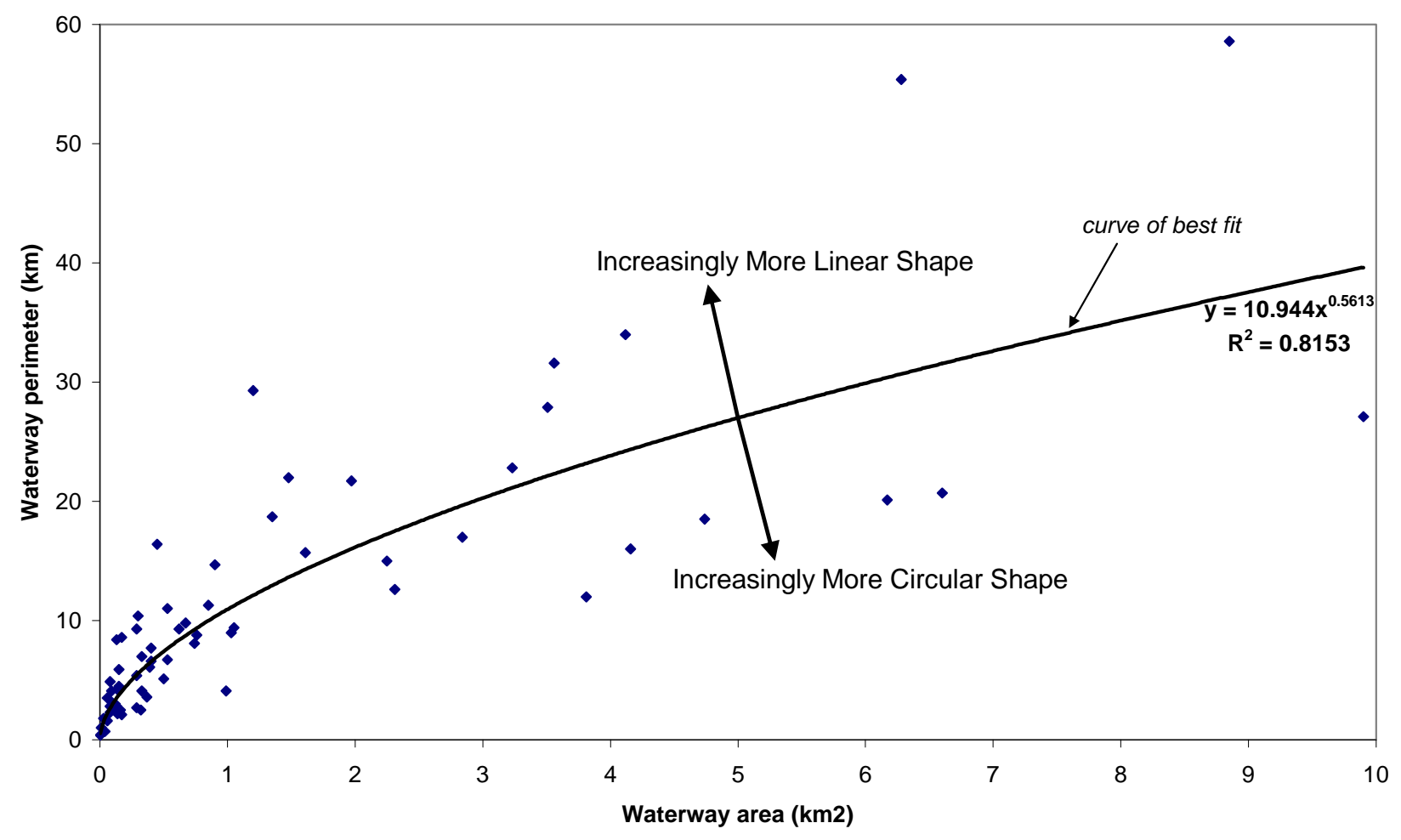

Figure 2. Relationship between waterway perimeter and waterway area for most NSW ICOLLs. The position of an ICOLL on this plot is used to measure waterway shape 


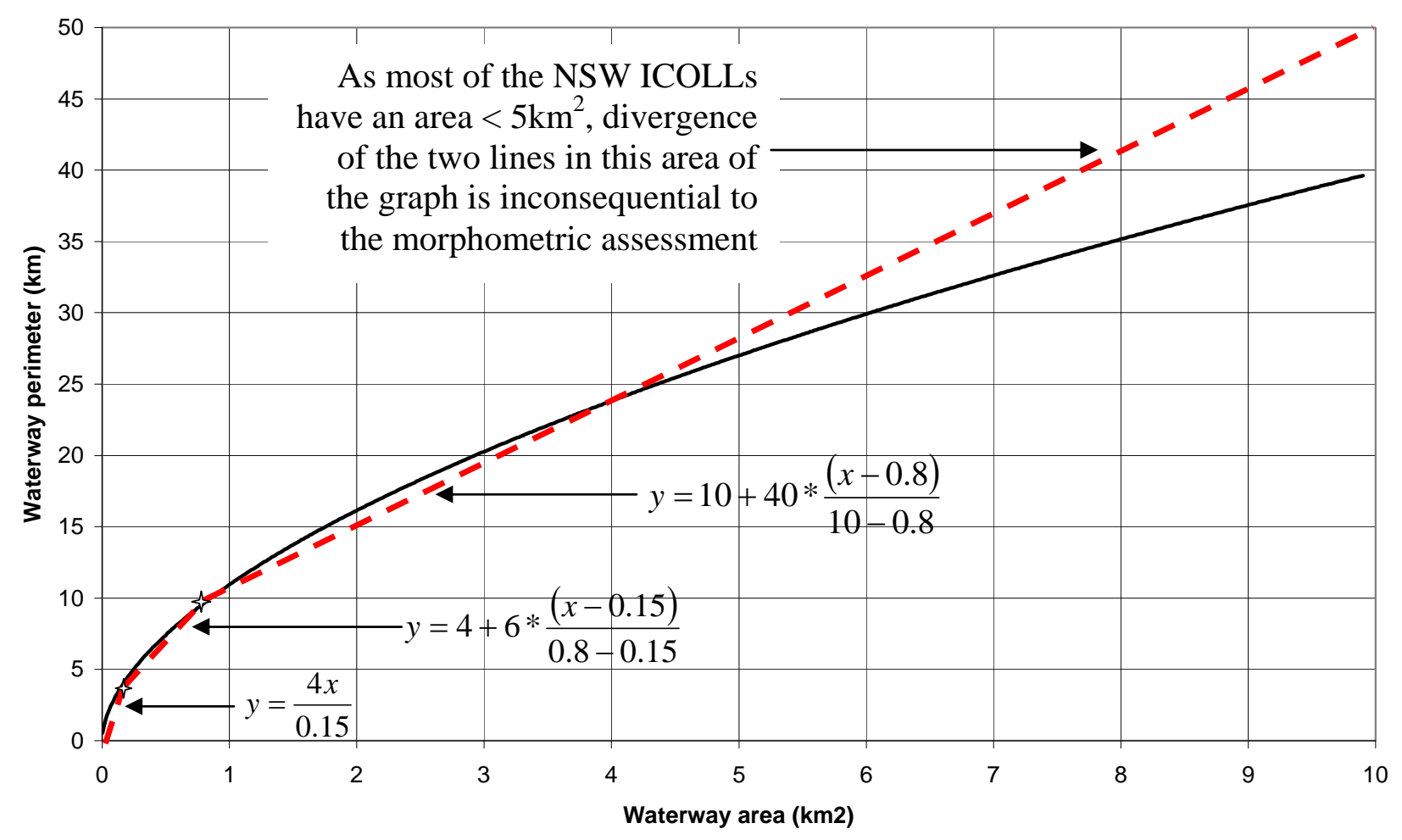

Figure 3. Stepped linear approximation of the curve of best fit shown in Figure 2. The vertices represent a change in the equation defining the relationship that is used to calculate shape function (Sf) 


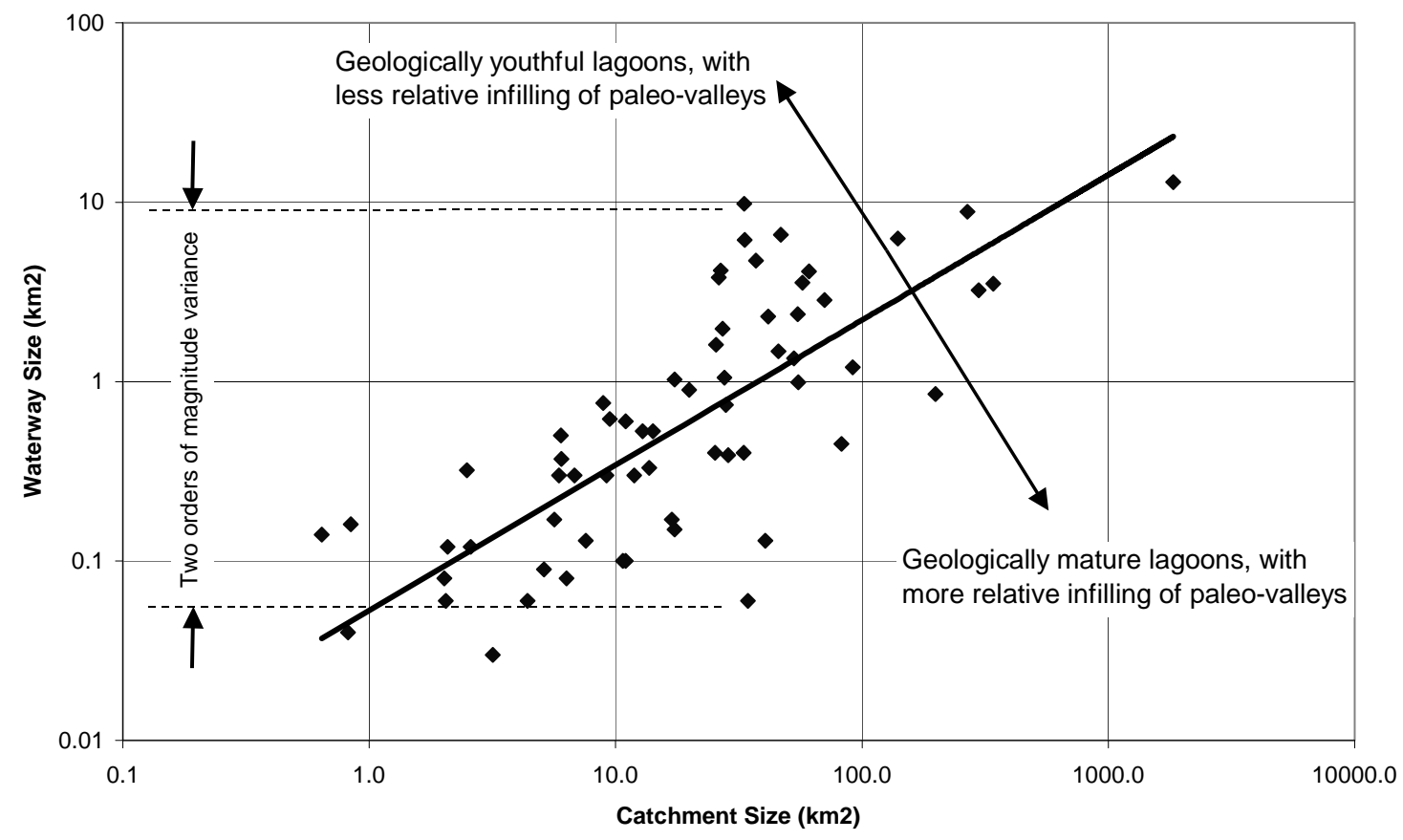

Figure 4. Relationship between catchment size and waterway size using data from most NSW ICOLLs 


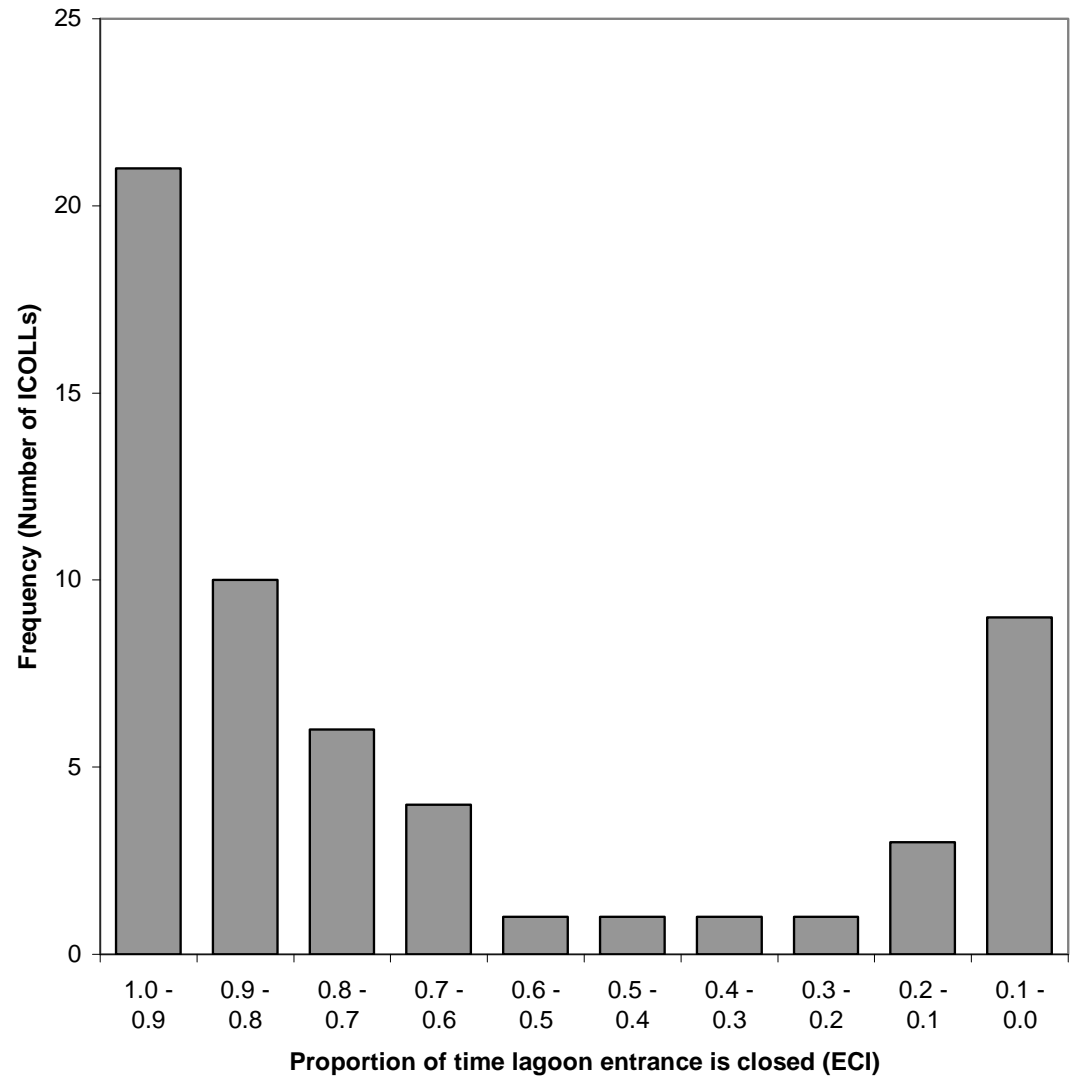

Figure 5. Distribution plot of Entrance Closure Indices for most NSW ICOLLs highlighting the bimodal nature of lagoon entrance as either mostly closed (with a high ECI) or mostly open (with a low ECI) 


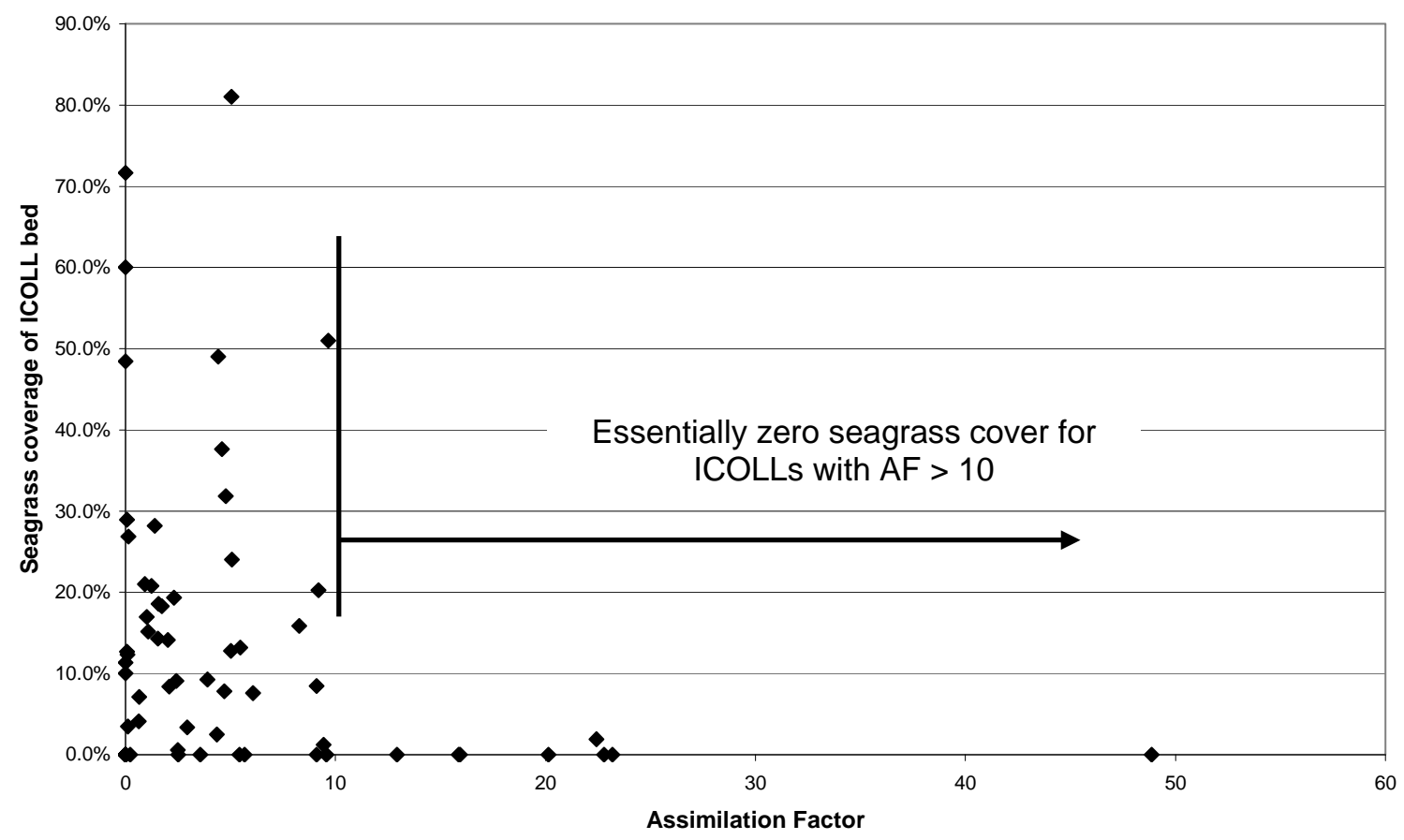

Figure 6. Relationship between the Assimilation Factor (AF) and seagrass coverage for most NSW ICOLLs.

Seagrass coverage is expressed as a percentage of the waterway area that contains seagrasses 